\title{
A Study on Translation of Bai Architectural Culture in Dali from the Perspective of Intercultural Communication
}

\author{
Luping Shang
}

Qujing Normal University, Qujing City, Yunnan Province, China

\begin{abstract}
Keywords: Intercultural Communication, Bai Architectural Culture; Cultural Communication Priority Principle, Target-language-reader-oriented Principle, Effective Communication.
\end{abstract}

\begin{abstract}
Translation is a communication activity involving different cultures. From the perspective of intercultural communication, this article attempts to propose the translating principles and solutions based on the analysis of the translation of Bai architectural culture and hopes to better achieve effective communication of distinctive ethnic culture.
\end{abstract}

\section{跨文化传播学视角下大理白族建筑文化英译研究}

尚路平

曲靖师范学院, 曲靖, 云南, 中国

关键词：跨文化传播学; 白族建筑文化; 文化传播优先原则; 译语读者接受心理中心原则; 有效传播

中文摘要：翻译是涉及到不同文化之间的传播活动。从跨文化传播学角度，以大理白族建筑 文化英译为个案研究, 分析现有英译中存在的问题, 提出跨文化传播学视角下的英译原则及 解决方案，以期更好地实现民族特色文化的有效传播。

\section{1. 引言}

传播是不同信息的交流、沟通与共享的过程。传播者不是简单地输出信息，接收者也不 是被动地接受信息，两者是动态的和互动的一一传播者和接收者之间是相互影响、交互作用 的 ${ }^{[1]}$ 。（孙英春, P47) 按照这种观点, 翻译活动事实上也是一种传播活动, 只是翻译是涉及 到不同文化之间的传播活动。大理白族建筑文化的英译就属于跨文化传播活动。本文拟从跨 文化传播学的视角, 以严家大院英译为个案研究, 找出现有大理白族建筑文化英译中存在的 问题, 并尝试提出相应的解决方案。

\section{2. 跨文化传播学理论及大理白族建筑文化英译原则}

跨文化传播既指来自不同文化背景的社会成员之间的交往与信息传播活动，也涉及各种 文化要素在全球社会中迁移、扩散、变动的过程，及其对不同群体、文化、国家乃至人类共 同体的影响 ${ }^{[1]}$ 。（孙英春，P13）跨文化传播学是把文化和传播作为其研究对象，并将文化领 域与传播领域的研究成果结合起来的一门综合性学科。翻译本质上是跨文化活动, 译者源语 信息的接收者，同时又是译语信息的传播者。传统的翻译理论把翻译过程看作是一个静态的 封闭的双语转换活动, 而随着传播学理论被引入到翻译领域, 翻译过程就不再是简单的静态 语言转换过程，而是一个开放的动态跨文化传播活动。

大理白族建筑文化英译是中华民族文化对外传播的一部分，是一种目的性很强的跨文化 传播活动。因此，文化的有效传播是至关重要的。根据跨文化传播理论，笔者认为在译者在 
翻译过程中需要遵循以下原则:

\section{1 大理白族建筑文化传播优先原则}

大理白族建筑文化英译旨在把中国灿烂多姿的民族文化传播到国际社会，让更多的人了 解到中国丰富的民族文化。因此，如何有效地将大理白族的建筑文化传播出去是译者首先要 考虑的问题。美国传播学四大奠基人之一的拉斯韦尔提出了经典的 $5 \mathrm{~W}$ 理论, 即传播过程由 传播主体、传播内容、传播媒介、传播受众和传播效果五要素构成。在五个要素中，居于核 心地位的是传播效果, 其他四个要素是传播效果的影响因素, 也是要为最终的传播效果服务 的。因此, 在大理白族建筑文化的英译过程中, 如何充分调动、协调四要素, 最终实现文化 最大限度的传播是译者在翻译过程中要首先考虑的。

\section{2 译语读者接受心理中心原则}

文化传播是一个信息交流和共享的互动过程。根据德国翻译理论家莱斯对文本类型的分 类，大理白族建筑文化是属于信息型文本。因此，大理白族建筑文化英译的目的是尽可能多 地让译语读者接收并理解相应的文化信息。由于中西方文化差异较大，生活在两种不同文化 中的人对于文本的理解和信息接受的方式有很大的不同。作为 $5 \mathrm{~W}$ 传播模式中的传播受众, 译语读者在很大程度上能够影响到最终的传播效果。因此, 译者在翻译过程中必须考虑到译 语读者的阅读期待和接受心理，在传播白族建筑文化的大前提下，以译语读者为中心，调整 翻译策略和方法，最大限度地实现源语信息的有效传播。

\section{3. 严家大院建筑文化英译评析}

严家大院是百年前云南巨富严子珍的宅院，位于大理喜洲古镇最繁华的四方街。大院始 建于清朝光绪 32 年 (公元 1907 年), 是喜洲规模最大, 保存最完整的一座白族建筑。作为全 国重点文物保护单位的严家大院，建筑形式保留了白族民居建筑“三坊一照壁”、“四合五天井”、 “走马转角楼”等典型的白族民居建筑风格, 向人们展示了白族建筑精美而独特的文化内涵。 大院中有一些建筑文化的介绍词及其英译, 笔者发现有些许不足, 因此, 选取两个具有代表 性的实例进行评析:

例 1: 四合五天井

Four Pavilions and Five Open Yards

“四合五天井”是白族民居中的一种特有的建筑形式，即由三开间四方硬山顶楼房、四个 双漏阁、四个小天井和一个大天井组成，俗称“四合五天井”。其建筑有单檐吊厦和重檐大出 厦等形式。楼上有多组“美女窗”封闭前廊厦台、楼下为开放式前廊, 整个院落上下贯通, 形 成了“走马转角楼”的格局。

"Four Pavilions and Five Open Yards" is special traditional architecture features in Bai residence. Four chambers with three room respectively are connected by four corner open yards and one main open yards. It could be single eave or multiple eaves, and upstairs space divided into front corridor and back chamber by sets of windows, while downstairs is open front corridor, the whole mansion is connected from upstairs to downstairs, making all chambers connected by different corridors.

例 2: 小洋楼 Western Style Mansion

建于一九三六年的小洋楼，是严家大院主人当年走南闯北接触了西方文化之后，在自己 后花园内建造的西方洋楼, 整座楼房的设计、施工人员都是从上海等地聘请, 建筑材料都是 从香港购买，在经海路、滇越铁路、公路、最后由马帮运至喜洲所建成，俗称“花园五号”。 此楼曾接待过军事理论家、第一任驻苏大使杨杰将军, 国民政府内政部长周钟嶽, 著名作家 老舍、著名画家徐悲鸿等政要名人。

严家在修建“花园五号”洋楼的同时, 有恰逢抗日战争爆发, 日本飞机已抵达滇西上空, 为保家人安全，继而在花园东南角修建了面积为 15 平方米的藏身室作为防空之用。 
Small building was a Western style building, built in 1936 in Family Yan's own backyard after Mr. Yan traveled across the world and started to learn Western culture. The designer and construction personnel were all from cities like Shanghai. building materials were bought in Hong Hong, transported via sea route, Yunnan-Vietnam Railway, inland road, and finally taken by horses to Xizhou. It was known "\#5 garden". The building had received military theorist and the first ambassador to Soviet Union general Yang jie, the national government's interior minister Zhou Zhongyue, famous writer Lao She, a famous painter xu beihuong and some other celebrities.

When Family Yan were building the Garden, the Anti-Japanese war broke out. Japanese plan invaded western Yunnan. To keep the family safety, then in the southeast corner of the garden a 15 square meters safe area were built for people to hide in time of air defense.

\section{1 漏译}

严家大院里对建筑文化的介绍属于“信息型”文本，其目的就是将大理白族建筑文化传递 出去, 因此, 翻译此类文本时, 译者应该考虑文本传播文化的预期目的, 在翻译过程中尽可 能的忠实地完整的讲原文中的文化信息翻译出来。如果随意删减或漏掉部分信息, 那么译文 读者就不能完整的了解原文要传递的信息。

例 1 中，译文漏掉了“硬山顶”和“四个双漏阁”，这是原文中关于白族建筑文化非常重要 的信息，笔者认为不应该被漏掉。因此建议在中心词“楼房”的译文前加上修饰性短语 “hard-hill-top/hardtop”; 并在译文中加上“four double-leaky pavilions”。

\section{2 翻译欠妥}

例 1 中，短语“三开间四方硬山顶楼房”被译为“Four chambers with three room”。白族建筑 中“四合五天井”的“四合”指的是院子的四个方向分别有一栋三间两层的楼房。笔者认为用 “chamber”来翻译“楼房”不太合适，因为“chamber”的含义更侧重于“卧室、接待室、单人套间”。 笔者建议用“building”来翻译“楼房”，整个短语可译作“four two-story hardtop buildings with three rooms in each story"。

例 2 中，标题“小洋楼”的译文是“Western Style Mansion”，笔者认为“mansion”一词翻译的 不合适。“Mansion”一词意为“大厦、宅邸”，侧重于表达建筑的整体性，而严家大院里的小洋 楼只是大宅院后花园里的一栋单独的楼房, 是整个严家大院的一部分。笔者认为, 把“小洋楼” 的“楼”翻译成“mansion”有些大了，用“building”就可以了。

\section{3 源语文化的选择性遗漏和背景知识的欠缺}

严家大院里对白族建筑文化的介绍涉及很多具有民族特色的词，少了对这些词背景知识 的介绍, 那么译文读者接收到的信息就是不完整的或是模糊的, 因此, 翻译原文中一些民族 特色词时加上相应的背景知识是十分有必要的。

例 1 中有两个白族建筑文化里的特色词“美女窗”和“走马转角楼”，其英文的介绍词对这 两个词选择了简化或解释性翻译。这在翻译过程中是非常常见的处理方法, 但是笔者认为, 在白族建筑文化的英译中，保留源语文化原汁原味的读音或意象是非常有必要的，因为白族 建筑文化英译的目的就是传播民族特色文化, 让译语读者体会不同的异域文化。当然, 译者 在翻译这两个词的时候可能是考虑到了行文结构或是篇幅受限等问题，对此，笔者认为可以 采用括号加注或是脚注的形式，对这两个词进行专门的补充说明。

例 2 中有几个文化特色词的翻译如果能加上一些背景知识, 那么译语读者便能更加清晰 明白的了解其内涵意义。如“马帮”, 译文将其简译为“taken by horses”,后面可以加上背景信息 “the main means of transportation on Ancient Tea-Horse Road in the southwestern part of China"; “国民政府”原译为“the national government”，后面可加上时间“1925-1948”; “抗日战争”原译为 “Anti-Japanese war”，后面可加上战争的起止时间“1931-1945”。 


\section{4 校对失误}

译文里也出现了名词单复数错误，大小写部分等细节上的问题，可将这些问题归为是校 对失误。如例 1 里的“Four chambers with three room”中的“room”, 此处应该是使用复数形式 “rooms”; 例 2 里的“building materials were bought”一句中“building”的首字母应该大写; 还有 一些地名人名拼写失误或不规范，如“Hong Hong”应改为“Hongkong”; “Yang jie”应改为“Yang Jie”; “xu beihong”应改为“Xu Beihong”; 专有名词“Anti-Japanese war”应改为“Anti-Japanese War”; 语法上的失误“When Family Yan were building the Garden”中的 be 动词应改为“was”。此 外，在句末单词换行时也出现了一些问题。这些问题看上去都是一些小问题，但是却会影响 译语读者阅读时的心情, 给他们留下不严谨不认真的印象。因此, 译文初稿完成后一定要反 复阅读, 反复校对。

\section{4. 结语}

跨文化传播学为民族文化的传播提供了一个全新的视角, 指出民族文化的有效传播是翻 译活动的最终目的, 同时还要考虑译文读者的接受心理, 以求达到最好的传播效果, 更有力 的推动中华民族文化的国际性传播。

\section{致谢}

本文为云南省教育厅科学研究基金项目 “云南大理白族建筑文化翻译研究（2015Y426）” 的阶段性成果之一。

\section{References}

[1] Sun Yingchun, Intercultural Communication: Global and Indigenous Perspectives [M]. Beijing: Peking University Press, 2015: p47; p13.

[2] Li Lifang and Qiu Hao, Ethnic Culture Communication: A Communication between the Present and History [J]. Academic Exploration, 2013(2): pp126-130.

[3] Dong Lu. Key Theories and Concepts in Communication (2nd Edition) [M]. Beijing: Peking University Press, 2016.

[4] Guo Jianzhong. Culture and Translation [M]. Beijing: China Translation \& Publishing Corporation, 2000.

[5] Zhuang Xiaodong. Culture Communication: the History, Theory and Reality [M]. Beijing: People's Publishing House, 2003. 